\title{
PARA ALIMENTAR O MUNDO: MODIFICAÇÕES GENÉTICAS, (IN)SEGURANÇA ALIMENTAR E OS RISCOS PARA A SAÚDE HUMANA E AMBIENTAL
}

\author{
J. Flávio Ferreira ${ }^{l}$
}

\begin{abstract}
RESUMO
Neste trabalho pretende-se tecer breves reflexões acerca da segurança alimentar face à utilização das chamadas "tecnologias transgênicas" que marcaram a Nova Revolução Verde (a $2^{\circ}$ R.V.) desde a década de 1990. No cerne do debate está uma crítica epistemológica aos paradigmas que projetam na relação do humano com a natureza (aqui destacada pela produção de alimentos) ideários de produtividade, dominação e de livre manipulação do meio-ambiente. Os benefícios emergentes de tais práticas nos discursos econômicos e políticos contrastam com os indícios de riscos à saúde humana ancorados em testes científicos: mais do que um movimento humanitário de "combate à fome", as políticas atuais de segurança alimentar vêm se apresentando como resultado prático de uma leitura [cientificista] da realidade tributária de paradigmas fundamentados em outras formas (proto)capitalistas do passado, como o colonialismo/imperialismo. Para entender este fenómeno de forma ampla, uma crítica epistemológica faz-se imperativa.
\end{abstract}

Palavras-chave: Transgênicos. Segurança alimentar. Biotecnologia. Epistemologia.

${ }^{1}$ Doutorando em Sociologia pelo Centro de Estudos Sociais, Universidade de Coimbra, Portugal. j.flavio.ferrer@gmail.com 


\title{
TO FEED THE WORLD: GENETICALLY MODIFIED FOOD, (IN)SAFE DIET AND THE RISKS TO HUMAN HEALTH AND THE ENVIRONMENT
}

\begin{abstract}
This article intends to discuss briefly the safe diet in view of the use of the so called "Transgenic Technologies" which have marked the New Green Revolution (the $2^{\circ}$ GR) since the 1990's. The debate revolves around an epistemological criticism of the paradigms which project ideals of productivity, domination and free use of the environment in the relation between man and nature (highlighted here because of its food production). The emergent benefits of such practices in the economical and political discourses contrast with the evidence of danger to human health, which are based on scientific experiments: more than a humanitarian movement of "fighting hunger", the current policies of safe diet have been presented as a practical result on how tributary reality of paradigms which are based on other forms of (proto)capitalism of the past, such as the colonialism/imperialism, is seen. In order to understand this phenomenon in a broad sense, an epistemological criticism is imperative.
\end{abstract}

Keywords: Genetically Modified Food. Safe Diet. Biotechnology. Epistemology.

Para compreender realmente a biotecnologia industrial e a engenharia genética, no entanto, é preciso reconbecer a sua gênese cultural. Como toda a ciência e tecnologia, a biotecnologia é uma construção social ou um artefato: a engenharia genética é a encarnação deliberada de uma cultura ocidental racionalista particular aplicada ao material genético de plantas e animais, incluindo os humanos. Na prática, a engenharia genética é a fabricação de uma vigorosa agenda corporativa à parte do que a natureza oferece (KNEEN, 1999, p. 162, tradução nossa).

\section{INTRODUÇÃO}

produção global de alimentos vem sendo elevada desde a massiva aplicação, a partir da década de 1990, das GES (genetically engineered seeds/sementes geneticamente modificadas). Este é um projeto que se desenha na atualidade e que, ao que tudo indica, fará parte do nosso quotidiano em um futuro próximo. No discurso político e na prática econômica estão problematizadas as necessidades de se alavancar o volume dos gêneros alimentícios para "combater a fome", para a 
estimulação econômica dos países emergentes e, como notamos há algum tempo nas primeiras páginas dos jornais, também dos países considerados desenvolvidos ${ }^{2}$.

0 crescimento populacional e os números alarmantes da insegurança alimentar ao redor do globo favorecem a perspectiva de que o investimento nesta área é crucial em termos humanos: seria a solução rápida para o contraste entre 0 aumento da produção de alimentos, as crises geradas pelas mais leves baixas no seu volume (como a crise de 2008 - quando a queda da produção dos cereais, em 2006, foi potencializada desde então com a crise energética e a subida do preço do petróleo e derivados; o que elevou tanto a procura por alimentos quanto os seus custos reais de produção e, consequentemente, o preço final ao consumidor) e, sobretudo, o alarmante número de famélicos ao redor do globo ${ }^{3}$.

Segundo a ONU, estima-se que cerca de 854 milhões de pessoas se encontravam em condição de má-nutrição em 2008, sendo a projeção para o pós-crise alimentar deste ano ascendente a um bilhão (à altura, um sexto da população mundial) de desnutridos ou pessoas em situação de forte carência alimentar/nutricional. 0 controle que se

\footnotetext{
${ }^{2}$ Esta seria, por exemplo, a vertente identificada por Escobar em After Nature: Steps to an Antiessencialist Political Ecology, de 1999, como "globalocêntrica": que situa as questões da biodiversidade mediante a exclusiva atuação científica, o planeamento nacional, o panorama econômico e político internacional e o desenvolvimento industrial/financeiro - desrespeitando, portanto, saberes locais, especificidades culturais e/ou regionais, os ciclos para que a terra se recomponha e introjetando na lógica da produção de alimentos valores economicistas e ocidentais. Os grandes defensores desta perspectiva são instituições "globais" como o Banco Mundial, o G8, o G20, a World Trade Organization, setores da United Nations e organismos nacionais com forte influência global, como a U. S. Food and Drug Administration (FDA), etc. 0 que têm em comum tais organismos é, provavelmente, a defesa de mecanismos que contribuem para a lógica neoliberal vigente e a defesa dos interesses econômicos daquilo que no campo sociológico se convencionou chamar de "países do Norte" por meio do lucro corporativo (ESCOBAR, 1999 apud SANTOS et al., 2004, p. 52). [Algumas das organizações aqui referidas foram adicionadas por mim, seguindo a proposta interpretava dos autores mencionados].

${ }^{3}$ Para mais detalhes explicados de forma relativamente acessível e ancorados a uma análise macroeconómica (ENTENDA..., 2008). 0 artigo ressalta como principais fatores estressantes da crise de 2008: (I) o desenvolvimento global (com o aumento do consumo nos países emergentes); (II) a questão populacional (ou o franco crescimento da população mundial na atualidade, com a ONU a projetar que atingiremos os 9 bilhões de pessoas em 2050); (III) as secas entre 2007 e 2008 (ou os períodos de estiagem que prejudicaram a produção do agronegócio nos grandes produtores mundiais como o Brasil e a Austrália - o que conferiu a diminuição das reservas agrícolas sem, no entanto, registar-se a diminuição da procura por alimentos); (IV) a alta do petróleo (ou o encarecimento dos combustíveis e, como consequência, dos meios de produção); (V) a especulação financeira: derivada da alta dos preços, diminuição dos estoques e aumento da procura dos produtos agropecuários; (VI) o enfraquecimento do Dólar enquanto moeda de negociação das commodities agrícolas; (VII) as altas generalizadas dos custos dos alimentos (advindas do efeito em cadeia gerado pela alta na produção agrícola - as rações, por exemplo, elevaram o preço das carnes e dos pescados); (VIII) o desvio de partes da safra de 2007 e 2008 para a produção de biocombustíveis; e (IX) a consequente quebra nas exportações pelo entrelaçamento de todos os fatores mencionados.
} 
verificou na produção agrícola global de 2009, após o ápice da crise atingida em 2008, não resultou na queda dos preços dos gêneros alimentares como se esperava; e, pior ainda, ao quadro numérico da insegurança alimentar foram acrescentados 100 milhões de pessoas então consideradas abaixo da linha da pobreza e, portanto, em dificuldades imediatas no acesso à alimentação básica (ou seja, em provável estado de subnutrição) ${ }^{4}$.

0 crescimento da produção agrícola não tem combatido a "fome no mundo". Nunca se produziu tanto alimento e nunca, ao mesmo tempo, a (in)segurança alimentar apresentou dados tão alarmantes. A questão, talvez, não seja 0 volume da produção agropecuária, mas a distribuição do que é produzido. A escassez de alimentos deve-se, na maior parte das vezes, à impossibilidade económica da sua aquisição e não pela escassez efetiva de alimentos no mercado (GOETTLICH, 2006; HOFFMANN, 1995; MALUF, 2007). Combater a fome, portanto, passa necessariamente por combater a desigualdade social e o sistema de acúmulo em que vivemos. Sem isso, o aumento na produção de alimentos não resolverá, como se tem assistido na prática, o problema da má-nutrição ou do acesso aos alimentos.

0 investimento maciço nas GES (sementes geneticamente modificadas) é o passo em disputa no cenário internacional. Obviamente, este movimento se encontra bem ancorado na pressão das grandes corporações pela diminuição dos protecionismos estatais e por parte das agências reguladoras para o consumo humano de tais produtos tecnológicos.

Os lucros de algumas empresas desde os primeiros lançamentos maciços das GES, entre 1994 e 1996, foram maiores do que o Produto Interno Bruto (PIB) de alguns países emergentes. 0 aumento das safras em determinadas partes do globo provocou um efeito em cascata nas políticas do agronegócio que refletiu as preocupações dos Estados com 0 mercado interno e com as exportações face ao fortalecimento da produção concorrente impulsionada pelas GES: dos Estados Unidos para o Canadá (com o milho e outros); da Argentina para o Brasil (com a soja, ou o "ouro branco", sobretudo), etc. Muitos Estados se viram obrigados a permitir temporariamente o plantio experimental das GES - que, entretanto, foi-se alargando em muitos dos casos às safras seguintes antes mesmo da formação de uma política nacional para a biotecnologia: a concorrência no mercado antecedeu a prudência na área da saúde e para com o meioambiente. Enquanto isso, os governos - apesar de algumas resistências como no caso da soja transgênica, no Brasil (ANDRIOLI, 2008) - dissimulavam não sentir a pressão da comunidade internacional para 0 fomento à investigação prévia/preventiva em

\footnotetext{
${ }^{4}$ Para mais informações consultar: The Secretary-General's High-Level Task Force on The Global Food Security Crisis, 2008. Disponível em: http://www.un.org/en/issues/food/taskforce/background.shtml. Acesso em: 5 maio 2012.
} 
detrimento da manutenção das suas exportações (GOETTLICH, 2006; KNEEN, 1999; SHRADER-FRECHETTE, 2005) $)^{5}$.

Esta sobreposição do "interesse nacional" motivado pelo quadro econômico/mercadológico global do agronegócio levanta uma série de questões: (I) quais seriam os danos causados potencialmente à saúde humana pelo consumo direto ou indireto (de animais que por sua vez foram alimentados com rações transgênicas, por ex.) dos cultivos das GES?; (II) quais são os impactos nos ecossistemas?; (III) quais seriam os pilares científicos que, justificando a utilização das GES, lançam à invisibilidade os efeitos nocivos daquilo a que 0 avanço tecnológico pretende de forma ideal combater (como a fome)?; (IV) o que, de fato, a utilização tecnológica das GES pode dizer-nos a respeito da nossa leitura científica da realidade e acerca, sobretudo, de nós mesmos em termos epistemológicos?

\section{IMPACTOS NA SAÚDE HUMANA}

Apesar do potencial do agronegócio hightech (engineered) no combate à fome e em prol da segurança alimentar (ou a produção de alimentos que assegure a demanda do mercado e a sua fluida distribuição), sabe-se (ou deduz-se), porém, que os seus efeitos orgânicos e os impactos ambientais podem ser incalculáveis, estando ainda pouco estudados quais seriam os custos humanos, ecológicos e econômicos do seu emprego e consumo a médio e a longo prazo.

Estima-se que a somatória dos cultivos da soja, milho, canola e algodão ao redor do globo resulte em cerca de 272 milhões de hectares, dos quais 25\% são explorados com culturas transgênicas, cujas áreas têm clara tendência de aumentar (ROESSING; LAZZAROTTO, 2004, p. 8). Estes números são dissonantes face à infraestrutura de regulação do cultivo baseado nas GES: as legislações nacionais sobre biotecnologia ficam aquém diante de tal cenário (ANDRIOLI, 2008); e os investimentos científicos que calculam os danos ambientais e à saúde humana pelo seu consumo (GENETICALLY..., 2012; SÉRALINI; CELLIER; DOMINIQUE, 2007) são geralmente

\footnotetext{
${ }^{5} 0$ primeiro grande caso internacional tocou especialmente o cultivo da soja aliada ao RR. 0 Roundup Ready (RR) é um herbicida aplicado às sementes geneticamente modificadas para resistirem à sua elevada concentração de tóxicos. A sua aplicação tem como finalidade matar as mais variadas ervas daninhas (inclusive as suas raízes, evitando que voltem a crescer e evidenciando, porém, a potência da sua destruição), diminuir as pragas e repelir, em muitos casos, os insetos. Este foi um grande marco na $2^{2}$ Revolução Verde sentido pelo mercado agrícola global. Este tipo de tecnologia, desenvolvida na década de 1970, viria a impor massivamente as formas da produção e do mercado em todo o mundo a partir da década de 1990. 0 RR, fabricado pela Monsanto Co., foi concebido, originalmente, com o glyphosate (glifosato) - substância que subsidiava o desenvolvimento das culturas bem como aniquilava as ameaças às grandes plantações.
} 
secundarizados em detrimento do lucro proferido pelo agribusiness bightech (GOETTLICH, 2006; KNEEN, 1999). Em meio a teses e antíteses no cenário científico, o único fato é: consumimos, informados ou não, protegidos por parâmetros legislativos/jurídicos ou não, após testes laboratoriais que esgotem os efeitos orgânicos das GES ou não, uma dose considerável de alimentos geneticamente modificados.

Embora seja um debate controverso, a nocividade dos GMOs (genetically modified organisms / organismos geneticamente modificados) à saúde humana pode ser deduzida de outros estudos realizados com animais e de fundamentos elementares da biologia - como mencionarei a seguir.

A Monsanto Co., detentora da maior fatia tecnológica e comercial das GES, realiza e/ou financia estudos sistemáticos a este respeito (dentre outras empresas que dominam em maior ou menos grau setores associados ao mercado na engenharia genética de sementes/alimentos, como a Bayer, BASF, Astra-Zeneca, DuPont, Novartis e Aventis - a maior parte destas enraizada na indústria química); sendo por isso, obviamente, colocada em questão a validação sempre positiva à sua comercialização ou neutral quanto aos efeitos do seu consumo nos resultados científicos obtidos.

No sítio oficial da Monsanto ${ }^{6}$ chama-nos a atenção um aviso By the year 2050 - 9 bilion people will need food, fuel \& clothing. How will it happen?? 0 anúncio, projetado no ano 2050, diz-nos não só que a Monsanto veio para ficar, mas que para além disso dela surgirá a solução para futuros problemas sociopolíticos e alimentares que envolvem cifras e números geoestatísticos inimagináveis para os dias de hoje inclusive em termos de retorno financeiro às corporações que administrarão tal cenário (GENETICALLY..., 2012; SÉRALINI; CELLIER; DOMINIQUE, 2007).

A engenharia genética, enquanto tecnologia que pode modificar qualidades genéticas e "induzir" a produção de determinados elementos estranhos à estrutura original do DNA de um organismo (para produzir proteínas ou enzimas distintas a uma qualidade $\mathrm{X}$, favorecer a resistência a um elemento (agro)tóxico Y, ou ainda fazer com que uma determinada cultura produza um "repelente" W a um inseto determinado, p.ex.), vem sendo empregue mais por questões econômicas do que propriamente pela

\footnotetext{
${ }^{6}$ Ver: http://www.monsanto.com/Pages/default.aspx; especialmente as informações contidas nos campos our pledge (o nosso compromisso), dentro de who we are (quem somos); e nas campanhas improving agriculture (melhorar a agricultura) e improving lives (melhorando vidas), em menção respectivamente ao crescimento da produção agrícola em países periféricos ou "emergentes" e à qualidade de vida das populações que usufruem tanto da oferta destes alimentos quanto do ganho nas expectativas de pequenos agricultores (pobres, em geral) que graças à tecnologia Monsanto puderam estabilizar as suas colheitas e melhorar as suas situações econômicas.

${ }^{7}$ Pelo ano 2050 - 9 bilhões de pessoas vão precisar de alimentos, combustivel e roupas. Como isso vai acontecer? (tradução nossa).
} 
segurança cientificamente inconteste do seu consumo. $0 \mathrm{RR}^{8}$, por exemplo, pôde ser utilizado graças às alterações genéticas de determinadas sementes GES (vendidas pela própria Monsanto) que tornam o seu cultivo resistente aos venenos especificamente projetados para cada tipo de cultura.

A este respeito, a Monsanto alega que: [...] 0 glifosato tem toxicidade muito baixa para a vida selvagem e que a exposição esperada aos usos aprovados dos produtos a base de glifosato não representam qualquer risco excessivo para a vida selvagem (MONSANTO COMPANY, 2002, p. 5, tradução nossa). Em outro ponto, encontramos a comparação dos efeitos à saúde humana entre a "agricultura comum" (ou com sementes "crioulas" e os "resíduos" que esta pode carregar de outras tecnologias herbicidas e/ou das condições do próprio terreno) e as GMOs. A Monsanto defende, a este respeito, que:

Depois que uma NOAEL [No Observed Adverse Effect Level] foi determinado que a EPA EUA [US Environmental Protection Agency] aplica fatores de incerteza para explicar as diferenças entre os seres humanos e os animais em teste, bem como a variabilidade dentre os indivíduos. A agência também considera os tipos de efeitos que foram observados em doses mais elevadas. Efeitos menos graves constituem normalmente uma margem inferior de exposição. A margem para 0 glifosato foi fixada em 100-fold, ao contrário de alguns outros pesticidas que têm margens de exposição de 1,000 ou mais devido a resultados toxicológicos menos favoráveis. Um fator de incerteza de 100-fold significa que a exposição humana aceitável para 0 glifosato foi estabelecida a um nível que é 100 vezes menor do que a dose de ensaio que não causou efeitos adversos observáveis (NOAEL) nos animais testados (MONSANTO COMPANY, 2002, p. 4, tradução nossa).

Este resultado, além de isentar o RR de riscos à saúde humana naturalizando-os a uma condição inerente ao meio (como resíduos e fatores próprios do terreno), acaba por inverter a situação ao reforçar as suas potencialidades no aumento garantido da produção aliado a um risco idêntico ou menor em termos de contaminação face aos alimentos produzidos pelas sementes crioulas (ou não-transgénicas).

À revelia, grandes quantidades de artigos podem ser encontradas em referência aos possíveis males provocados pelo consumo alargado dos GMOs; inclusive pela falta [ainda] de dados laboratoriais, muitos destes são desacreditados pelos estudos patrocinados pela Monsanto. Diante das críticas de cientistas e ONGs internacionais, como a Food \& Wather Wacht (FWW), a Monsanto vem sistematicamente utilizando o

\footnotetext{
${ }^{8}$ Roundup Ready, ver nota 5, neste trabalho.
} 
nome de cientistas reconhecidos na área da engenharia genética para justificar o seu rigor científico. Tais artigos, cujos estudos são atualizados periodicamente, defendem a falta de elementos que comprovem os malefícios à saúde pelos GMOs em detrimento das suas vantagens econômicas/de produção. Um exemplo seria 0 relatório referente também à utilização do RR baseado num estudo toxicológico cuja escrita se resguarda mais em chaves legitimadoras da posição da companhia do que na apresentação de dados científicos propriamente rigorosos. Segundo a Monsanto, o RR foi [mais uma vez] testado por três toxicologistas reconhecidos internacionalmente numa rigorosa publicação cuja conclusão foi: "[...] uma apreciação peer-reviewed de avaliação de segurança e do risco do glifosato quanto à formulação original do herbicida Roundup" (WILLIAMS; KROES; MUNRO, 2000 apud MONSANTO COMPANY, 2005, p. 1, tradução nossa).

Por sua vez, Andrioli (2008, p. 2) defende que:

As experiências realizadas com cobaias alimentadas com soja transgênica cultivada em condições normais (que contêm até $33 \mathrm{mg}$ de resíduos de glifosato por $\mathrm{Kg}$ ) chegam a outros resultados: a ocorrência de alterações na estrutura do fígado e do sangue, causada por produtos metabólicos desconhecidos em função de efeitos posicionais do gene resistente ao herbicida, como também em função de efeitos conhecidos de resíduos de superdoses de herbicidas e seus derivados.

Apesar de muitos dados recentes demonstrarem os potenciais efeitos nocivos das GES na saúde humana, os resultados de diferentes investigações acerca dos efeitos adversos do consumo dos GMOs permanecem antagônicos. Tanto a FDA como os inúmeros relatórios científicos ligados ao setor privado parecem indicar com maior frequência a ausência de danos oriundos do seu consumo: Até o momento, não há efeitos adversos para a saúde atribuidos à engenharia genética documentados na população humana (NATIONAL ACADEMY OF SCIENCES, 2004, p. 8, tradução nossa).

No que tange ao panorama europeu - que inicialmente opôs-se ao cultivo das GES, em meados da década de 1990 - o Directorate-General for Research and Innovation, Biotechnologies, Agriculture and Food (DG RIBAF) da Comissão Europeia divulgou em extenso relatório baseado em 81 projetos envolvendo os mais variados experimentos na área da engenharia genética em cerca de 400 laboratórios, a defender que:

A principal conclusão a retirar dos esforços em mais de 130 projetos de pesquisa, cobrindo um período de mais de 25 anos de estudos, envolvendo mais de 500 grupos de pesquisa independentes, é de que a biotecnologia, e em particular os GMOs, não são per se mais arriscados do que, por exemplo, tecnologias convencionais de melhoramento das plantas. Outra conclusão 
muito importante é a de que a pesquisa biotecnológica de hoje em dia e as suas aplicações são muito mais diversificadas do que eram há 25 anos, ponto este também refletido pelo atual $7^{\circ}$ programa-quadro da U. E. (EUROPEAN COMMISSION, 2010, p. 16, tradução nossa).

Todas as problemáticas direta ou indiretamente envolvidas neste tema emergem de forma diferenciada mediante a pergunta que se deseja fazer. Os estudos toxicológicos acerca do consumo dos GM0s terminam com "nada indica que os GMOs causam diretamente algum efeito nocivo à saúde humana" ou "ainda não é seguro afirmar que o consumo prolongado dos GM0s não causará danos à saúde". Apesar da assertividade que afasta da visão o risco à saúde humana e fomenta a continuidade das culturas GES, estas conclusões deixam transparecer também o seu contrário. Parece-nos que há uma problemática na preposição, ou seja, como o risco não é provado não se faz necessário, $a$ priori, provar a sua ausência antes do consumo em massa do milho ou da soja GES.

Além disso, foi na década de 1970 que o RR foi desenvolvido, embora o cultivo que the tem por base tenha sido iniciado em meados da década de 1990 e se tornado massivo desde meados dos anos 2000. Isso quer dizer que possivelmente ainda não se tenha consumido transgênicos por tempo suficiente para que, havendo de fato alguma nocividade na sua ingestão, possamos ter registros de largos fenômenos patológicos em parcelas populacionais. Embora o DG RIBAF defenda que 0 avanço da engenharia genérica nos últimos 25 anos se faça notar (passando-nos uma ideia de sobre-segurança em respeito aos seus produtos derivados em face ao "não registo de efeitos patológicos neste período") sabe-se, porém, que o consumo massivo de soja GES é bem mais recente: o que não nos permite avaliar a situação com grande precisão.

Por outro lado, estudos que utilizaram cobaias apontam graves anomalias orgânicas após a exposição destas aos GMOs. Séralini, Cellier e Dominique (2007), por exemplo, revisitaram os dados laboratoriais sobre os riscos do consumo do milho transgênico a propósito da permissão europeia para o seu cultivo, em 2005. Logo depois da divulgação dos processos de análise, a sua equipe (a qual reanalisou os testes) chegou ao seguinte resultado:

Observou-se que, após o consumo de M0N863 [um tipo de milho transgênico], ratos apresentaram ligeiras variações - embora significativamente relacionadas às doses [de M0N863] - no crescimento em ambos os sexos, resultando numa redução de 3,3\% no peso dos machos e aumento de 3,7\% no peso das fêmeas. Medições químicas revelaram sinais de toxicidade hepatorrenal, marcada também pela diferença de sensibilidade entre machos e fêmeas. As triglicérides aumentaram entre 24 e 40\% nas fêmeas [...], o fósforo na urina e o sódio na excreção diminuíram nos machos entre 31 e $35 \%$ [...] nos resultados significativamente mais 
importantes relacionados com 0 tratamento em comparação com sete dietas testadas. (SÉRALINI; CELLIER; DOMINIQUE, 2007, p. 596, tradução nossa).

Como resultado, os autores defendem que Experimentos mais longos são essenciais a fim de indicar a verdadeira natureza e extensão da patologia possivel; com os dados actuais, não pode concluir-se que o milho GM MON863 é um produto seguro (SÉRALINI; CELLIER; DOMINIQUE, 2007, p. 596).

Alguns testes chegaram a constatar modificações estruturais e celulares em órgãos e tecidos (MALATESTA et al., 2008; SÉRALINI; CELLIER; DOMINIQUE, 2007; VECCHIO et al., 2004); noutros, como no experimento de dois anos com roedoras em fase adulta - segundo os autores, o mais longo de que se tinha notícia à altura - não foram constatados efeitos adversos gritantes no consumo de soja transgênica face ao grupo de controle alimentado com uma dieta normal (EUROPEAN FOOD SAFETY AUTHORITY, 2008; MALATESTA et al., 2008;). As alterações nos tecidos e órgãos das cobaias, embora apresentadas em algumas etapas analíticas, não poderiam levar à conclusão de que os GMOs realmente causam efeitos adversos no organismo humano.

Vecchio et al. (2004), apesar do caráter implicitamente mais contestatário à liberalização do plantio com as GES em suas investigações, acabam também por terem de se posicionar pela imprecisão dos resultados obtidos face ao panorama geral em questão; ou seja, tanto nas pesquisas que põem em prova, quanto as que defendem em maior ou menor grau o consumo dos GMOs a falta de estudos de referência mais aprofundados thes impedem, sem grandes diferenciações, de chegar a conclusões finais acerca dos danos (ou da sua ausência) no consumo dos alimentos engeeriered:

Estes achados sugerem que, durante 0 intervalo de 2 a 8 meses, uma diminuição transitória da transcrição ocorre em ratos alimentados com uma dieta GM. De fato, durante este período aglomerados de PG (que são conhecidos por conterem pré-mRNA: Fakan, 2004), foram encontrados em todos os tipos de células examinadas; [...] A(s) causa(s) das alterações observadas não podem ser conclusivamente estabelecidas nesta fase da pesquisa. No entanto, uma vez que a soja GM utilizada no presente estudo foi a resistente ao glifosato (tendo sido, por consequência, tratada no campo com tal herbicida), não se pode descartar que os efeitos observados podem ser devidos a resíduos do herbicida. Consistente com esta hipótese, os traços de glifosato foram realmente detectados na moagem e no pão da soja GM tratada (GRANBY apud VECCHIO et al., 2004, p. 452, tradução nossa).

Apesar das evidências de alterações orgânicas acima mencionadas, grande parte das equipes de investigação é obrigada a reconhecer que a ausência de estudos 
prolongados em mamíferos impede uma afirmação inabalável acerca dos efeitos nocivos do consumo humano dos GMOs. De toda a forma, Malatesta et al. (2008, p. 975, tradução nossa) conclui, e cito:

Em conclusão, o presente trabalho demonstra que a ingestão de soja GM [geneticamente modificada] pode influenciar características morfofuncionais do fígado ao longo do processo fisiológico do envelhecimento e, embora os mecanismos responsáveis por tais alterações ainda sejam desconhecidos e que alguns dados sejam discutidos em caráter especulativo, há diversos achados sublinhando a importância de continuar a investigar as consequências em longo prazo de uma dieta GM, bem como os seus potenciais efeitos sinérgicos pelo envelhecimento, condições xenobióticas e/ou de estresse.

\section{DOMINAÇÃO, APROPRIAÇÃO E O MEIO: CIENTIFICISMOS E EPISTEMES}

Para Bruno Latour a nossa forma de pensar os objetos, a natureza, a nós mesmos e às formas concepcionais entre os humanos e os dois primeiros advém da sua relação. Pela Teoria do Ator-Rede (LATOUR; WOOLGAR, 1997), pode-se compreender que a realidade não existe per se, como a realidade da natureza e/ou a realidade do homem sobre esta e sobre si mesmo, mas antes pela relação entre as duas partes que, apoiada no advento da ciência e do seu papel interpretativo (e auto legitimador) do mundo, produzirá uma percepção hegemónica do que é a realidade. 0 laboratório, portanto, funciona como uma ferramenta para que se possam realizar operações e eventos, mas também como uma "fábrica de fatos", como edificador do social (LATOUR, 1994) e como arcabouço epistêmico para os primados do próprio sentido depositado na "modernidade": esta última, por sua vez, um desdobramento dos fundamentos interpretativos da realidade do Iluminismo à luz da tecnologia e das suas promessas na sociedade.

Para uma "antropologia simétrica" (enquanto ciência reconfiguradora e de caráter desconstrucionista), a vantagem de se analisar a realidade através da relação entre "humanos" e "não-humanos" está ancorada na ampliação perceptiva dos processos que baseiam a realidade e que causam problemas práticos (sociais e políticos, p. ex): a distinção entre a natureza e a racionalidade humana produz fatos, que por sua vez carecem de medidas a serem tomadas.

Mas este processo não esgota todas as variantes que compõem o que a própria ciência constitui como fato. 0 que Latour nos quer dizer, em outras palavras, é que a realidade científica é uma pequena fração das possibilidades de realidade criadas a partir das dicotomias entre corpo e mente e entre racionalidade e natureza; e, portanto, que (a) 
temos formas de conceber a realidade que provocam problemas secundários pelo seu prisma reducionista face ao panorama geral e (b) que as consequências de todo este processo são tão incalculáveis quanto irrelevantes para a primeira parte (a) devido à sua própria limitação.

Alguns exemplos podem ajudar a elucidar tal processo: Amos (2011) traz-nos uma problemática ecológica que desenrola o cultivo das GES e as suas consequências para o meio. Segundo o autor, o contato das abelhas selvagens no norte dos EUA (responsáveis pela polinização de diversas flores e árvores frutíferas) com o cultivo das GES está provocando-lhes a morte. Como consequência da modificação genética das culturas e produção massiva de flores para o mercado, o pólen estará sofrendo alterações que fazem com que as abelhas fiquem doentes ou então acabem por enfrentar a falta de nutrientes que se encontram, por isto mesmo, rarefeitos no meio. Testes têm indicado, a este propósito, a alteração celular do aparelho gástrico das abelhas bem como a incidência de descoloração do aparelho intestinal (apontando anomalias na absorção dos alimentos) como efeitos à exposição destas aos transgênicos. A sua morte, portanto, é potencializada pela elevada utilização dos agrotóxicos a que tais culturas são geneticamente desenhadas para serem imunes, sendo também resistentes a "pragas" e insetos. Como resultado, além da morte das abelhas (bem como de outros insetos e, possivelmente, de animais ao longo da cadeia alimentar) a coleta de mel selvagem tem baixado consideravelmente (fato que afeta a dieta da fauna local), a polinização naquela área estará em franco declínio, e uma série de outros efeitos em cadeia decorrerão seguramente deste recorte da morte das abelhas.

Andrioli (2008, p. 1) por sua vez, levanta a má qualidade do milho transgênico, que "contém em todas as suas células uma toxina produzida por uma bactéria que nela foi introduzida para combater determinados insetos e outro milho com resistência a um herbicida, que pode ser aplicado sobre a planta, com maior índice de resíduos." 0 risco à saúde humana faz-se presente tanto pelo seu consumo quanto pelo consumo de animais que foram alimentados com o milho GES. Mas uma grave característica que nem mesmo está presente em muitas das investigações acerca dos efeitos das GES é a da sua progressiva eliminação das lavouras crioulas ao seu redor, pois "se trata de uma planta com polinização aberta e cruzada, na qual a contaminação de lavouras impede qualquer possibilidade de coexistência entre cultivos transgênicos e convencionais" (ANDRIOLI, 2008, p. 1).

Estes dois exemplos, em termos epistemológicos, trazem-nos a limitação da ciência pela própria imposição cognitiva daquilo que deve ser considerado como realidade e, portanto, base factível para o desenvolvimento científico. Estamos, pois, a tratar daquilo a que a filosofia da tecnologia (para fazer referencia a uma nova área nas 
humanidades) reproblematizou como "racionalidade epistêmica"". Ou seja, o múltiplo processo (histórico, político, econômico, cultural, etc.) que define o pensamento credível do incredível: os limites do que deve ser considerado racional e levado em conta para que o mundo seja compreendido, para que o conhecimento seja sistematizado, regularizado, mesurável, revisitável, enfim, para que um processo de acúmulo de conhecimento tornese inteligível, ou para que a ciência produza parâmetros universais para a interpretação da realidade (LATOUR; WOOLGAR, 1997).

Este ponto de vista revela-nos, sob o tema dos transgénicos, o hiato que existe entre a dicotomia "humano" e "não-humano", representando - assim como nas bases científicas que viabilizaram o que se convencionou chamar de "modernidade" - a racionalidade e a matéria que então objetificada tem como único destino ser dominada e servir aos propósitos do conhecimento humano. Em termos práticos, isto significa que à medida que a relação com o meio norteia por contraposição o sentido do que é 0 humano e a sua perspectiva de si e do conhecimento que acumula sobre o primeiro, os efeitos da ciência tendem a ser definidos pela sua racionalidade epistêmica, sob a qual o papel da natureza é apenas servir o seu dominador.

Mediante o potencial produtivo da tecnologia em termos do cultivo, da política, da economia e do próprio conhecimento sobre a natureza, a instabilidade derivada deste avanço (como o efeito em cadeia no ecossistema e na saúde humana pela morte das abelhas e a predação consequente da prevalência do milho GES que acabará progressivamente com o milho crioulo) não será plenamente considerada. Todos os processos que extrapolem os paradigmas de governança sobre a natureza e que considerem valores humanos para além dos constituídos como dominação dos segundos sobre os primeiros estarão fora de uma "racionalidade epistêmica", não serão, pois, considerados como conhecimentos/parâmetros válidos.

Londa Schiebinguer (1998), por exemplo, chama-nos a atenção para um processo ao longo da constituição da ciência imperial que implica na formação do paradigma científico moderno: através da história da Flos Pavonis, uma planta utilizada pelas populações locais no Suriname colonial pelos seus efeitos abortíferos, fazse notar como o sistema classificatório proposto por Lineu no campo da biologia possibilitou a formação de uma ciência em termos universais no contexto colonial e na própria formação do campo científico em geral ${ }^{10}$. Como nos demonstra a autora, o

\footnotetext{
${ }^{9}$ A racionalidade epistêmica pode ser entendida a partir do que foi conhecido como "paradoxo de Moore", considerado por Wittgenstein como um dos maiores contributos de Moore à filosofia. Para uma análise detalhada sobre o paradoxo de Moore e as suas implicações filosóficas à racionalidade (ALMEIDA, 2009).

${ }^{10} 0$ poder abortífero da Flos Pavonis era utilizado pelas mulheres escravas como forma de estas evitarem que a gestação chegasse ao fim, uma vez que sabiam que o nascimento de um filho implicava automaticamente no nascimento de um novo escravo. A forma de quebrarem este ciclo fazia-lhes abdicar da maternidade. Mas o ponto em questão é a relação entre conhecimento e poder, onde a medicina local
} 
movimento de uniformização da linguagem da botânica e da biologia possibilitou com que o conhecimento científico fosse mesurável e revisitável para a produção de medicamentos, bem como o avanço na área médica e econômica; ao mesmo tempo, é inegável que a sistematização científica imperial invisibilizou as relações coloniais: em primeiro lugar, o conhecimento já não poderia ser local, mas sim universal. Este, deveria ser aplicado no campo medicinal após o seu reenquadramento conceitual de acordo com os cânones científicos, passando a necessitar da autorização/regulação do cientista e do físico para ser aplicado. Como resultado, eliminou-se toda a diversidade semântica e usos "étnicos" dos recursos naturais que estavam envoltos por outras lógicas e epistemes que teriam sido perdidos com o tempo. 0 que Schiebinguer nos quer dizer está ligado à dominação do meio pela ciência, à sobreposição de saberes locais, a um sentido único na interpretação do humano e no desenvolvimento de uma forma hegemônica que apagou práticas concorrentes ao longo da história colonial. A sua conclusão é a de que a ciência produziu (e produz) conhecimento à custa da produção de ignorância.

Este desconhecimento pode ser lido como as outras possibilidades que ficaram fora dos limites de uma "racionalidade epistémica", lido como irracional e, portanto, irrelevante ao pensamento científico. A sua forma de considerar a natureza (sempre como objeto) elimina qualquer possibilidade de inserção do humano como sua parte não dominante, incluindo nesta relação vertical a utilização dos seus recursos e a preservação dos seus ciclos e necessidades específicas.

Em termos de uma epistemologia crítica, a detenção do conhecimento na área científica possui não só elementos históricos e políticos, mas antes econômicos. A essência do que aconteceu na ciência imperial, à esteira da história da Flos Pavonis, está permeada de interesses financeiros como as rotas coloniais de comércio e a expansão territorial para as colónias; justificou-se, pois, como movimento necessário ao estabelecimento de condições para o colonizador.

Uma perspectiva contemporânea do entrelaçamento destes fatores é colocada por muito críticos da ciência bightech a título das culturas GES. Kneen (1999, p. 161-163), dentre outros, defende que o economicismo (embora o autor não faça uso deste termo) presente na engenharia genética, apesar da sua capacidade para a larga produção de alimentos, é impulsionado, sobretudo, pela possibilidade de obtenção de lucro.

A utilização de estudos científicos e da tecnologia GES não pode, portanto, navegar em direção a um porto ecológico considerando-se o seu impacto no meio e na

lhes deixava margem e certa autonomia - dentro do contexto político da época, para uma reação contestatária ao sistema e para o cuidado de si e da família. 
saúde humana: eis aqui um tributo contemporâneo da dicotomia entre natureza e razão.

\section{CONSIDERAÇÕES FinAIS}

0 campo epistemológico vem sendo um pano de fundo muito útil para que se possam aprofundar as discussões acerca das problemáticas atuais numa sociedade globalizada: em termos dos efeitos e impactos de uma decisão político-econômica, quanto aos fluxos humanos, no debate jurídico, nas problemáticas culturais e identitárias emergentes e, sobretudo, na revisitação dos pilares que sustentam a nossa interpretação da realidade. Enquanto campo de disputa, a emergência da engenharia genética como meio tecnológico na produção alimentar - seja pelo crescimento da população mundial, seja pelo combate à fome que se nos apresenta sob números alarmantes em termos sociais - não dispensa um reposicionamento no campo reflexivo voltado aos fatores epistemológicos (bem como às suas raízes) no panorama científico contemporâneo.

Aparentemente, o crescimento do cultivo das GES sem a prévia (e adequada) investigação quanto ao seu posterior consumo em termos de risco à saúde humana e ao meio ambiente apresenta consequências ainda incalculáveis. A criação de patentes dos frutos deste processo estaria em conformidade com essa "racionalidade epistémica" que se nos coloca, que se reapresenta (ou que simplesmente permanece) na recente história da ciência tal qual esta é por nós conhecida. A partir do momento em que a engenharia genética produz novos tipos de culturas/alimentos (sob o sistema de patentes), acaba-se tanto por gerir o controle privado sobre a vida como, em última análise, por dificultar a agricultura familiar e de médio porte (não destinada ao sistema de plantation) pelo perigo colocado à sobrevivência das sementes crioulas - como descrito anteriormente com relação ao milho.

0 Capital envolvido na expansão das GES/GMOs pretende estabelecer 0 monopólio da produção de determinados alimentos, restringindo a circulação de sementes crioulas e forçando, com isso, o acúmulo de terras por parte de grandes grupos empresariais. A "esterilidade-funcional" das sementes GES (inutilizáveis mediante a não utilização dos princípios ativos que as fazem desenvolver) revela a precariedade e a autonomia extirpada do pequeno agricultor. Os efeitos na economia e em termos ecológicos se fazem evidentes.

Este processo pode ser interpretado sob múltiplas questões ecológicas: I. o esgotamento das terras pelas monoculturas, uma vez que a sua ostensividade desrespeita ciclos de recomposição do solo e provoca uma super-utilização de fertilizantes químicos e pesticidas cada vez mais potentes (de $2^{\circ}$ e/ou $3^{\circ}$ gerações, p.ex.); II. a desestruturação 
da agricultura familiar, que de fato é o tipo de cultura que alimenta internamente um país; III. a interiorização do modus hegemónico neoliberal na gestão do território e quanto aos seus efeitos na saúde humana (como a contaminação dos solos, dos afluentes, o acúmulo de substâncias tóxicas na produção agrícola potencializado pelos herbicidas ultra concentrados cujos transgénicos são projetados para serem resistentes); com efeito, deriva-se daí uma múltipla atuação tanto no acúmulo de terras no agronegócio quanto como o lobby para que os GMOs sejam livremente comercializados sem os testes necessários para comprovar a sua nocividade a longo prazo; IV. a privatização dos "materiais genéticos" que progressivamente - com a utilização mitigada das sementes crioulas - poderão ser a única solução para a agricultura no futuro: o milho para exportação, por exemplo, é referido pela sua especificidade genética: tipo "MON 810", "NK 603", ou "MON 863",; e V. o comprometimento progressivo da diversidade biológica que estará, dessa forma, submetida a "efeitos dominó" em termos ecológicos e em decorrência das GES, cujos resultados são catastróficos. A saúde humana, sob este prisma, é parte deste processo.

Devido aos pontos acima mencionados - principalmente sobre o monopólio das sementes GES em detrimento das crioulas - um grupo constituído por representantes de 18 países africanos no encontro da Organização para o Alimento e a Agricultura das Nações Unidas resolveu manifestar-se em uníssono: as tecnologias genéticas... vão minar a nossa capacidade de alimentar-nos (SHRADER-FRECHETTE, 2005, p. 137, tradução nossa) A lógica que permeia a tecnologia da engenharia genética parece, pois, mais ligada à intenção humana do que um espelhamento de um conhecimento científico que prime pela vida e pela quebra de paradigmas que, empregues em escalas nunca dantes vistas na história, acabarão por causar efeitos humanos e ecológicos irreversíveis ao meio e à nossa saúde.

\section{REFERÊNCIAS}

ALMEIDA, Cláudio. Racionalidade epistêmica e o paradoxo de moore. Veritas, Porto Alegre, v. 54, n. 2, p. 48-73, maio/ago. 2009.

AMOS, Brit. Death of the bees. genetically modified crops and the decline of bee colonies in North America. Global Research - Centre for Research on Globalization. Aug. 2011. Disponível em: <http://www.globalresearch.ca/index.php?context=va\&aid=25950>. Acesso em: 20 maio 2012.

\footnotetext{
${ }^{11}$ Sendo este último tipo justamente o que foi aprovado, em meados de 2005, pelos meios regulatórios europeus e que, após indícios de alteração orgânica patológica em médio ou longo consumo em organismos expostos às suas qualidades específicas (GES), foi questionado como potencialmente danoso à saúde humana. Para os testes laboratoriais detalhados (SÉRALINI; CELLIER; DOMINIQUE, 2007.
} 
ANDRIOLI, Antônio Inácio. 0 escândalo da liberação de transgênicos no Brasil. Revista Espaço Acadêmico, Maringá, n. 82, p. 1-3, mar. 2008. Disponível em:

$<$ http://www.espacoacademico.com.br/082/82andrioli.pdf>. Acesso em: 16 maio 2012.

ENTENDA a crise dos alimentos. Folha Online, 25 abr. 2008. Mercado. Disponível em: $<$ <ttp://wwwl.folha.uol.com.br/folha/dinheiro/ult91u395708.shtml>. Acesso em: 6 maio 2012.

EUROPEAN COMMISSION. A decade of EU-funded GM0 research (2001 - 2010).

Brussels: European Commission, 2010. Disponível em:

$<$ http://ec.europa.eu/research/biosociety/pdf/a_decade_of_eu-

funded_gmo_research.pdf>. Acesso em: 17 maio 2012.

EUROPEAN FOOD SAFETY AUTHORITY - EFSA. Safety and nutritional assessment of GM plants and derived food and feed: the role of animal feeding trials": report of the EFSA GM0 panel working group on animal feeding trials. Food and Chemical Toxicology, Oxford, n. 46, p. S2-S70, 2008.

GENETICALLY engineered food: an overview. Washington: Food \& Water Watch, 2012. Disponível em:

$<$ http://documents.foodandwaterwatch.org/doc/GeneticallyEngineeredFood.pdf>. Acesso em: 7 maio 2012.

GOETTLICH, Paul. Will genetically engineered foods feed the world? 2006. Disponivel em: <http://www.mindfully.org/GE/GE4/Feed-The-World-GMOs.htm>. Acesso em: 14 maio 2012.

HOFFMANN, Rodolfo. Pobreza, insegurança alimentar e desnutrição no Brasil. Estudos Avançados, São Paulo, v. 9, n. 24, p. 159-172, 1995.

KNEEN, Brewster. Restructuring food for corporate profit: the corporate genetics of Cargill and Monsanto. Agriculture and Human Values, Netherlands, n. 16, p. 161-167, 1999 .

LATOUR, Bruno. Jamais fomos modernos: ensaio de antropologia simétrica. Rio de Janeiro: Ed. 34, 1994.

LATOUR, Bruno; WOOLGAR, Steve. A vida de laboratório: a produção dos fatos científicos. Rio de Janeiro: Relume Dumará, 1997.

MALATESTA, Manuela et al. A long-term study on female mice fed on a genetically modified soybean: effects on liver ageing. Histochemistry and Cell Biology, Berlin, v. 130, n. 5, p. 967-977, 2008.

MALUF, Renato Sergio Jamil. Segurança alimentar e nutricional. Petrópolis, Rio de Janeiro: Vozes, 2007. 
MONSANTO COMPANY. Backgrounder: glyphosate and standard toxicology studies. 2002. Disponível em: <http:/www.monsanto.com/products/Documents/glyphosatebackground-materials/gly_tox101_bkg.pdf>. Acesso em: 6 maio 2012.

. Backgrounder: summary of human risk assessment and safety evaluation on Glyphosate and Roundup ${ }^{\circledR}$ Herbicide. 2005. Disponível em:

$<$ http://www.monsanto.com/products/Documents/glyphosate-backgroundmaterials/gly_human_risk.pdf>. Acesso em: 7 maio 2012.

NATIONAL ACADEMY OF SCIENCES. Safety of genetically engineered foods: approaches to assessing unintended health effects. Washington: National Academies Press, 2004.

ROESSING, Antônio Carlos; LAZZAROTTO, Joelsio José. Soja transgênica no Brasil: situação atual e perspectivas para os próximos anos. Londrina: Embrapa, 2004.

Disponível em:

$<$ http://www.cgee.org.br/busca/ConsultaProdutoNcomTopo.php?f=1\&idProduto=1860 >. Acesso em: 16 maio 2012.

SANTOS, Boaventura de Sousa. et al. (Org.). Semear outras soluções: os caminhos da biodiversidade e dos conhecimentos rivais. Porto: Afrontamento, 2004.

SCHIEBINGUER, Londa. Lost knowledge, bodies of ignorance, and the poverty of taxonomy as illustrated by the curious fate of flos pavonis, an abortifacient. In: JONES, Caroline ; GALISON, Peter (Ed.). Picturing science, producing art. New York: Routledge, 1998. p. 125-144.

SÉRALINI, Gilles-Eric; CELLIER, Vendomois; DOMINIQUE, Jöel Spiroux. New analysis of a rat feeding study with a genetically modified maize reveals signs of hepatorenal toxicity. Archive of Environmental Contamination and Toxicology, New York, v. 52, n. 4, p. 596-602, May 2007.

SHRADER-FRECHETTE, Kristin. Property rights and genetic engineering: developing nations at risk. Science and Engineering Ethics, England, v. 11, n. 1, p. 137-149, 2005.

VECCHIO, L. et al. Ultrastructural analysis of testes from mice fed on genetically modified soybean. European Journal of Histochemistry, Pavia, v. 48, p. 449-454, 2004.

WILLIAMS, Gary M.; KROES, Robert; MUNRO, Ian C. Safety evaluation and risk assessment of the herbicide roundup and its active ingredient, glyphosate, for humans. Regulatory Toxicology and Pharmacology, New York, v. 31, p. 117-165, 2000. 